Staff Paper No. 77

\title{
Exchange Rate Asymmetry and Flexible Exchange Rates under Inflation Targeting Regimes:

\author{
Evidence from Four East and Southeast Asian Countries
}

Victor Pontines and Reza Y. Siregar

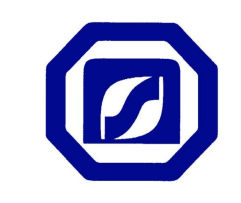

The South East Asian Central Banks (SEACEN)

Research and Training Centre

(The SEACEN Centre)

Kuala Lumpur, Malaysia 


\title{
Exchange Rate Asymmetry and Flexible Exchange Rates under Inflation Targeting Regimes: \\ Evidence from Four East and Southeast Asian Countries
}

\author{
Victor Pontines a and Reza Y. Siregar ${ }^{b}$
}

August 2010

a. Victor Pontines (corresponding author) is with the Flinders Business School, Australia. E-mail: victor.pontines@flinders.edu.au

b. Reza Y. Siregar is with the South East Asian Central Banks (SEACEN) Research and Training Centre in Kuala Lumpur, Malaysia.E-mail: reza@seacen.org and rezasiregar@yahoo.com.

The views expressed in this study are those of the authors alone and may not necessarily represent the views of their affiliated institutions. Research support from Nurulhuda Mohd Hussain is duly acknowledged. 


\section{Table of Contents}

Page

Abstract $\quad$ iv

1. Introduction $\quad 1$

2. Background

2.1. Inflation Targeting Regime in East Asia: Brief Introduction 3

2.2. Exchange Rate Volatility and Exchange Market Pressure 3

3. Empirical Approaches $\quad 7$

3.1 Smooth Transition Autoregressive (STAR) Model $\quad 7$

3.2 Markov-regime Switching 8

4. Empirical Results 9

5. Concluding Remarks $\quad 11$

$\begin{array}{ll}\text { References } & 13\end{array}$

\section{List of Tables}

Table 1: Estimation Results for LSTR2 Models of East Asian Currencies 15

Table 2: Diagnostic Test Results for LSTR2 Models of East Asian Currencies 16

Table 3: Estimation Results for LSTR2 Models of the Australian Dollar 17

Table 4: Diagnostic Test Results for LSTR2 Models of the Australian Dollar 18

Table 5: Threshold Values $\quad 19$

Table 6: Estimation Results for Regime Switching Models of East Asian Currencies 20

Table 7: Estimation Results for Regime Switching Models of the Australian Dollar 21

Table 8: Transition Probabilities $\quad 22$

\section{List of Figures}

Figure 1: Monthly (\%) Exchange Rate Change against the US Dollar 23

Figure 2: KLR EMPs $\quad 24$ 


\begin{abstract}
We demonstrate that the economies of Indonesia, Korea, Philippines and Thailand, which are among the first group of emerging markets to embrace the inflation targeting framework of monetary policy, tend to adopt a form of an asymmetrical exchange rate behaviour wherein appreciation pressures are restrained more substantially than depreciation pressures. In short, these four Asian economies exemplify aversion to appreciations such that greater flexibility is allowed only one side of the market. Formal econometric tests using the smooth transition autoregressive and the Markov regime switching models confirm this hypothesis of aversion to appreciation and show that the central banks of these four economies tend to tolerate more of depreciations than of appreciations of their local currencies against the US dollar.
\end{abstract}

Key Words: $\quad$ Exchange Rate Asymmetry Inflation Targeting; Fear of Floating; Fear of Appreciation; Regime Switching Models.

JEL Classifications: E58; F31; F41 


\section{Introduction}

In light of the importance of the Chinese yuan in rebalancing world economic growth, the exchange rate policy of the People's Bank of China (PBC) has expectedly consumed discussions and debates at the highest levels of international bilateral and multilateral policy meetings, including the G20 meetings. The announcement by the PBC on Saturday, 19 June 2010, that it will again insert more flexibility into its exchange rate is being heralded as a significant economic step. On the following Monday, the yuan appreciated as much as $0.4 \%$ against the US dollar, the highest one day increase since the currency was first regularly traded. On top of this, the Chinese monetary authority asserted that a large revaluation of the yuan against the US dollar is indeed in the country's longterm interest. It still remains to be seen, however, if this new announcement will materialise in actuality towards more aggressive upward trends in the yuan, particularly against the US dollar. We already know that before the mid-2005, the PBC announced a similar policy intention to allow the currency to move more flexibly. The outcome was arguably a more measured and deliberate approach akin to a managed crawl whereby the currency was allowed to appreciate by around 20\% against the dollar from 2005 to late 2008.

Therefore, announcements of intentions to move to greater flexibility are not new and unique as is with this most recent announcement of the PBC in allowing greater flexibility in the yuan. In fact, as what Calvo and Reinhart (2002) have vividly demonstrated in their seminal paper, there is a divide between what official labels and announcements suggest to what is practiced in actuality. A case in point which our study pays particular attention to is the collective experiences of Indonesia, Korea, Thailand and the Philippines in the aftermath of the East Asian crisis. Immediately after the 1997 East Asian crisis, the monetary authorities of these economies announced their commitments to abandon their rigid soft-US dollar policies and let their currencies float more flexibly. Furthermore, to regain confidence in their domestic monetary policies, the central banks of these economies had officially adopted inflation targeting policy regimes. Intrinsically, the exchange rate is expected to move more flexibly under the inflation targeting policy.

Against this backdrop, the central contention of this paper is that while the adoption of the inflation targeting policy may lead to more flexible exchange rate movements, it is still however possible for various reasons, that the degree of flexibility is significantly higher on one side of the market. ${ }^{1}$ In other words, the monetary authorities in these four Asian economies can asymmetrically manage their exchange rates wherein they can allow for some currency depreciation while substantially limiting the extent of currency appreciation. For lack of better alternatives, this exchange rate intervention

\footnotetext{
${ }^{1}$ See, for instance, Stigler et al (2009) for this various set of plausible reasons.
} 
behaviour has been coined by Levy-yeyati and Sturzenegger (2007) as 'fear of floating in reverse' or 'fear of appreciation'. ${ }^{2}$

There has indeed been, a number of recent works (though not many), that examines such aversion of central banks to exchange rate appreciations in East Asia. Ramachandran and Srinivasan (2007), for instance, employ a simple dummy variable to account for depreciations and appreciations. On the other hand, Srinivasan, Mahambare and Ramachandran (2008) explore a cubic loss function to account for possible asymmetric behaviour. The study of Stigler, Patnaik and Shah (2009) apply time series techniques in the context of structural change of the exchange rate regime. Furthermore, Pontines and Rajan (2010) similarly employs the cubic loss function of Srinivasan et al (2008) and tests the model that not only includes India, but across a broader set of emerging Asian economies that are known to operate a variety of managed floats viz., Indonesia, Korea, Philippines, Singapore, and Thailand.

Our study extends these earlier studies in a number of ways. To start with, we work only on East Asian countries that have officially announced the adoption of a more flexible exchange rate regime together with the implementation of an inflation targeting policy. ${ }^{3}$ Hence, in this study, we recognize the importance of the nominal policy anchor in the set of countries that we have selected. This is particularly important as the degree of exchange rate flexibility should arguably be influenced by the choice of the monetary policy regime. Previous studies in general agree that a credible IT regime requires a considerable degree of exchange rate flexibility (Mason, Savastano and Sharma (1997) and Fischer (2001)). Moreover, in a recent work, Brenner and Sokoler (2010) examine the implementation of the IT regime in Israel and further argue that the presence of exchange rate target bands often undermines the credibility of the IT regime. In particular, the authors claim that when the exchange rate is not allowed to appreciate beyond a certain arbitrary rate, the monetary policy transmission channel to influence inflation would be greatly undermined.

Another marked delineation of our study from the earlier ones is with the thorough empirical approaches used. This study employs two classes of regime-switching models that takes account of this asymmetry in exchange rate behaviour. As far as the first class of regime switching model, we show that in order to capture this form of behaviour, one needs to explicitly measure the thresholds on both sides of the market, i.e., appreciation and depreciation thresholds. Once this is done and a straight forward comparison of both these thresholds is made, a divergence in the magnitudes is interpreted as a telltale indication of asymmetric exchange rate behaviour on the part of monetary authorities. To this end, we employ a certain type of the smooth transition autoregressive (STAR) model

\footnotetext{
${ }^{2}$ Such asymmetry in exchange rate behaviour have been pointed out much earlier by Almekinders and Eijfinger (1996) when they find that during the post-Louvre period, US and German central banks have tried to counteract appreciations of their currency more strongly than depreciations.

${ }^{3}$ To serve as a benchmark, we also examine the movements of the Australian dollar against the US dollar. Australia is among the first group of economies that adopted the inflation targeting regime.
} 
known as the LSTR2 model. The main advantage of using the LSTR2 model is that unlike other variants of the STAR model, it allows one to explicitly include two thresholds in the transition function instead of just one. This affords us a convenient test procedure that exactly fits the aim of this paper.

In order to provide confirmatory evidence from the test results emanating from the STAR-LSTR2 model, the second class of regime switching model known as the Markov regime-switching is also employed. Under this framework, we treat asymmetry in exchange rate behaviour as being equivalent to evidence of persistence. Testing for the presence of persistence is then achieved via the comparison of transition probabilities across two different regimes. To the best of our knowledge, our paper is the only one thus far that employs both techniques in the context of flexible exchange rate policies under the inflation targeting regimes in East Asia. ${ }^{4}$

In the next section, we present a brief background on the adoption of inflation targeting in East Asia and also undertakes an analysis of key stylised trends in the data. An empirical section (Section 3) follows which includes a discussion of the model specifications and econometric testing employed. The key empirical findings are analysed and highlighted in Section 4. A brief concluding section ends the paper.

\section{Background}

\subsection{Inflation Targeting Regime in East Asia: Brief Introduction}

Prior to the outbreak of the 1997 East Asian crisis, only five economies officially adopted the inflation targeting (IT) regime as a framework for conducting monetary policy. More interestingly, all five were developed economies and none were economies from the Asian region. ${ }^{5}$ This landscape changed drastically during the next decade. By the end of 2006, around 26 countries had joined the IT group and more than half were developing economies.

Amongst the Asian economies, Korea was the first to officially adopt the IT regime in April 1998, and the framework was implemented in accordance with the revision of the Bank of Korea Act ${ }^{6}$. Meanwhile, the central banks of the Philippines and Thailand were the

\footnotetext{
${ }^{4}$ The paper that comes very close to our work is by Leon and Najarian (2005) which adopts a similar set of comprehensive tests but undertakes it in the context of deviations from PPP. In addition, Stigler et al (2009) also adopts threshold modeling procedures but uses the self-exciting threshold autoregressive (SETAR) process and the momentum threshold autoregressive model (MTAR) in approaching the issue of asymmetric exchange rate behaviour.

${ }^{5}$ These five developed economies were New Zealand (1990), Canada (1991), United Kingdom (1992), Australia (1993) and Sweden (1993).

${ }^{6}$ According to Article 6 of the Bank of Korea Act, the BOK determines the annual inflation target for each year in consultation with the government, and it formulates and announces its plan for the operation of monetary policy inclusive of the target. Moreover, the BOK should at most, strive to achieve the inflation target.
} 
next set of Asian economies to embrace the IT regime in 2000. However, Indonesia which had announced its intention to pursue the IT regime in May 1999, only officially launched and fully implemented an explicit price stability management in July 2005.

Despite the timing differences, each of these Asian economies shares a number of common rationales for embracing the IT regime. Prior to their adoption of the IT regime, the central banks of these four economies place a lot of emphasis on the management of their monetary aggregates. However, with further liberalisation of their capital accounts and deepening of the countries' financial sectors, these central banks found it increasingly difficult to manage their respective monetary aggregates. Another shared motive is the recognition that the relationships between monetary indicators, price stability (inflation) and output growth were becoming less stable, especially in the immediate aftermath of the 1997 financial crisis and the rapidly changing financial sector domestically and regionally. ${ }^{7}$ In addition, the implementation of IT is expected to restore the credibility as well as the independence of these countries' central banks (Jansen, 2001).

Studies have also shown that the exchange rate is an important channel through which monetary policy can affect inflation (Svensson (2000) and Haldane and Batini (1998)). This channel of monetary policy transmission is undermined, however, when the exchange rate is not allowed to appreciate beyond a certain arbitrary rate. A greater degree of exchange rate flexibility is needed to mitigate inflation expectation. Examining the case of inflation targeting policy in Israel, Brenner and Sekoler (2010) has further argued that inflation targeting policy is not sustainable under the presence of foreign exchange band regime. In reality, policy intervention in the foreign exchange market do occur, even under the IT regime. In the following section, we will examine closely the nexus between the stylised trends in exchange rates of the four East Asian economies that we are investigating and the international reserve accumulation behaviour of these economies in the aftermath of the East Asian crisis.

\subsection{Exchange Rate Volatility and Exchange Market Pressure}

According to the IMF (2005), full implementation of the inflation targeting (IT) policy starts when the two following features are satisfied --when the central bank is officially given the full mandate, and when the central bank commits officially to a numerical target in the form of a level or range of annual inflation. Based on these basic principles, one can then consider that the full and official IT period started explicitly in the second quarter of 1998 in the case of Korea, in the second quarter of 2000 in Thailand, in the first quarter of 2002 in the Philippines, and finally, during the third quarter of 2005 in the case of Indonesia. We use these individual official IT starting dates as our beginning

\footnotetext{
${ }^{7}$ The globalised banking system in particular has been evident in many parts of the world, including in Asia. The post-1997 East Asia financial crisis has witnessed the rise in the share of local banks in these crisis-effected economies being controlled by foreign investors, predominantly multi-national banks. We also have seen the rise of regional multi-national banks in these Asian economies (Siregar and Lim (2010)).
} 
post-crisis reference period to calculate the standard deviations of the monthly changes of the local currencies of these four Asian economies against the US dollar until end-2006, and compare these to a similarly calculated standard deviations of the monthly changes of the same currencies this time during the pre-crisis period of 1990-1996. Overall, we clearly find that, with the lesser exception of the Philippines peso, the currencies of these Asian countries have become more volatile during the IT period, suggesting a move towards a more flexible exchange rate policy. In the case of the Thai baht, for instance, the standard deviation during the IT period (quarter 2, 2000 - quarter 4, 2006) was more than three times than during the pre-1997 East Asian crisis (1990-1996). Indeed, a visual inspection of Figure 1 alone will show clearly right away, again with the lesser exception of the Philippines and ignoring the intervening years of the 1997-98 East Asian crisis, that there has been a marked shift of these countries to greater exchange rate flexibility after the crisis.

Yet, we would like to emphasise that a seeming move to a flexible exchange rate policy does not necessarily tantamount to a policy that attaches equal importance to a currency appreciation and depreciation. As documented in earlier seminal works, countries either often intervened more to limit the dread of sudden or large currency depreciation (Calvo and Reinhart (2002) or to otherwise, strongly fear a sudden or large currency appreciation (Levy-Yeyati and Sturzenegger (2007)). In other words, even under an observed shift of the four Asian countries to flexible exchange rate regimes, the pursuit of an active exchange rate policy as part of a 'leaning against the wind exchange rate policy' may still be the norm. ${ }^{8}$ To initially investigate the possibility of what can be labeled as an asymmetrical exchange rate regime, we resort to a useful and commonly applied concept of exchange market pressure (EMP) index in the spirit of Kaminsky et al (1998) and Kaminsky and Reinhart (1999), which can be can be formally expressed as follows: .

$$
E M P_{i, t}=\frac{\Delta e_{i, t}}{e_{i, t}}-\frac{\sigma_{e}}{\sigma_{r}} \frac{\Delta r_{i, t}}{r_{i, t}}+\frac{\sigma_{e}}{\sigma_{\text {int }}} \Delta \text { int }_{i, t}
$$

where $\left(E M P_{i, t}\right)$ is the exchange market pressure index for country $(i)$ in period $(t) ; e_{\mathrm{i}, \mathrm{t}}$ is the unit of country $i^{\prime} s$ currency per US dollar in period $t ;\left(\sigma_{e}\right)$ is the standard deviation of the rate of change in the exchange rate $\left(\frac{\Delta e_{i, t}}{e_{i, t}}\right) ;\left(r_{i, t}\right)$ is the gross foreign reserves of country (i) in period $t$; and $\left(\sigma_{r}\right)$ is the standard deviation of the rate of change in reserves $\left(\frac{\Delta r_{i, t}}{r_{i, t}}\right)$;

\footnotetext{
${ }^{8}$ As previously noted, the earlier study of Almekinders and Eijffinger (1996) find that during the post-Louvre period, US and German central banks have already tried to counteract appreciations of their currency more strongly than depreciations
} 
$\left(\right.$ int $\left._{i, t}\right)$ is the nominal interest rate for country $(i)$ in period $t$, and $\left(\sigma_{\text {int }}\right)$ is the standard deviation of the change in the nominal interest rate, $\left(\Delta\right.$ int $\left._{i, t}\right)$.

As contrasted from similar constructions of the EMP index, ${ }^{9}$ one can gauge from the above equation that different weights are given to the three key components of the exchange market pressure index. In particular, the weights of the interest rate and reserve fluctuations depend on the relative size of their standard deviations $\left(\left(\sigma_{r}\right)\right.$ and $\left(\sigma_{\text {int }}\right)$, respectively) against that of the exchange rate $\left(\sigma_{e}\right)$. Hence, a positive (negative) EMP index suggests the presence of selling/depreciation (buying/appreciation) pressures against the local currency.

On this basis, a closer inspection of monthly trends of the exchange market pressure indices indicate that on average more than half (around 55\%) of the total observations of the monthly EMP indices in the cases of Indonesia, Philippines and Thailand take on negative values (Figure 2). In the particular case of Korea, the share of negative values of the monthly EMP series was even higher at around two-thirds (or about $67 \%$ ) of the total observations. These trends suggest that these currencies, especially the Korean won, were under more intense buying or appreciating pressures than of selling or depreciating pressure during the period of observation. It is not surprising, therefore, that once we go into the details, in terms of paying closer attention to the individual components of the EMP series, evidences of monthly reserve accumulation accompanied by monthly appreciations of varying degrees of the local currencies against the US dollar are reported across all countries. ${ }^{10}$

Combining these two evidences of buying/appreciation pressures and reserve accumulation, one cannot dismiss the possibility of a 'leaning against the wind' policy stance that the central banks of these countries have adopted during the period of observation. The common objective behind any 'leaning against the wind' policy is to manage the volatilities of the exchange rate. The stylised trends of the EMP values suggest that the central banks of these four Asian economies actively manage the appreciation pressures against the local currency, particularly against the US dollar.

\footnotetext{
${ }^{9}$ See, for instance, Eichengreen et al $(1995,1996)$.

${ }^{10}$ In the case for Thailand for instance, the reserve position increased by over $1 \%$ on monthly basis from January 2002 to December 2006, while the baht appreciated at around $0.3 \%$ per month. A slower phase of reserve accumulation than in Thailand was accounted for the case of Indonesia, together with the mildest monthly rate of rupiah appreciation at around $0.2 \%$. Korea reported the fastest monthly rate of reserve accumulation at an average of slightly below $1.5 \%$ from January 2002 to December 2006. At the same time, the won appreciated at an average of $0.6 \%$ per month for the same period. Arguably the Philippines reported the slowest phase of reserve accumulation, together with a monthly exchange rate appreciation of the peso at around the rate reported for the won.
} 
In short, we have a rather conflicting message. On one hand, there has clearly been a rise in the volatility of these four East Asian currencies against the US dollar, suggesting a move towards flexible exchange rate regimes on the part of their monetary authorities. At the same time, however, the trends and individual components of the EMP provide indications of policy interventions to manage the volatility of the local currencies. More importantly, the initial evidences also show that the efforts tend to be bias toward mitigating appreciation pressures than those of depreciation pressures. Hence, there seem to be evidences of asymmetrical exchange rate intervention behaviour. To test more conclusively the presence of policy bias toward managing appreciation pressures, the next section introduces the two empirical tests that our study adopts to verify the asymmetrical exchange rate policy stance.

\section{Empirical Approaches}

\subsection{Smooth Transition Autoregressive (STAR) Model}

The STAR model is a non-linear time series model that allows the variable under investigation, which in the present case is denoted as $\Delta \ln e x r$, to be first differenced of the log of the nominal exchange rate (local currency per US dollar) to smoothly adjust every moment within the different regimes. This model may be written as:

$$
\Delta \ln \operatorname{exr}=\alpha_{0}+\sum_{i=1}^{p} \alpha_{i}\left(\Delta \ln \operatorname{exr}_{t-i}\right)+\left[\beta_{0}^{*}+\sum_{i=1}^{p} \beta_{i}^{*}\left(\Delta \ln \operatorname{exr}_{t-i}\right)\right] F\left(\Delta \ln \operatorname{exr}_{t-d}\right)+\varepsilon_{t}
$$

where $\alpha_{0}$ is the linear intercept term; $\alpha_{\mathrm{i}}(i=1, \ldots, p)$ is the linear autoregressive parameters; $\beta_{0}^{*}$ is the nonlinear intercept term, $\beta_{1}^{*}(i=1, \ldots, p)$ standing for the nonlinear autoregressive parameters, $F\left(\Delta \ln e x r_{t-d}\right)$ is the transition function which characterises the smooth transition between 2 regimes that depends on the lagged term of the first difference of the log of the nominal exchange rate, $\Delta \ln \operatorname{exr}_{t-d}$ where $d$ is the delay lag length, and $\varepsilon_{\mathrm{t}}$ is a white noise with zero mean and constant variance.

The theoretical and empirical aspects of this model are rather involved and extensively discussed in a number of studies. Interested readers should refer to Terasvirta and Anderson (1992) and Dijk et al. (2002) for a thorough discussion of STAR models. Nonetheless, depending on the specification of the transition function, the natural starting point in describing the STAR model is the two-regime LSTR1 model with the following general logistic transition function, which takes values in the interval between zero and one:

$$
F\left(\gamma, c ; y_{t-d}\right)=\frac{1}{1+\exp \left(-\gamma\left(y_{t-d}-c\right)\right)}, \quad \gamma>0
$$


where: $\gamma$ is the slope parameter (the magnitude of which measures the speed of transition between the two regimes), $c$ is the threshold parameter (the value of which indicates the location of the transition) and $y_{t-d}$ is the transition variable with the associated delay parameter $d$.

It turns out that a variant of the LSTR1 model is well-suited to test whether East Asian currencies exhibit aversion to appreciations. In particular, one can resort to the LSTR2 model as suggested in Terasvirta (1998). ${ }^{11}$ The transition function of the LSTR2 model is the second-order logistic function:

$$
F\left(\gamma, c_{L}, c_{H} ; y_{t-d}\right)=\frac{1}{1+\exp \left(-\gamma\left(y_{t-d}-c_{L}\right)\left(y_{t-d}-c_{H}\right)\right)}, \quad \gamma>0
$$

Note that the LSTR2 transition function resembles the transition function of the LSTR1 model but that the LSTR2 transition function involves two threshold parameters $c_{L}$ and $c_{H}$. These lower $\left(c_{L}\right)$ and upper $\left(c_{H}\right)$ threshold parameters can be utilised to test for asymmetrical exchange rate behaviour as these thresholds reflect the relative tolerance of monetary authorities to exchange rate variations. To be more specific, if the upper threshold, $c_{H}$ is larger than the (absolute value of the) lower threshold, $c_{L}$, this suggests an aversion of monetary authorities to currency appreciations.

\subsection{Markov-regime Switching}

We now turn to the second empirical approach used in this paper to test for the existence of asymmetrical exchange rate behaviour via the Markov-regime switching. Denoting again $\Delta \ln e x r$ as the first difference of the log of the nominal exchange rate (local currency per US dollar), we estimate a univariate regime switching model which can be written in the form:

$$
\Delta \ln \operatorname{exr}_{t}=\alpha\left(s_{t}\right)+\sum_{k=1}^{p} \alpha_{k}\left(s_{t}\right) \Delta \ln \operatorname{exr}_{t-k}+\sum\left(s_{t}\right) \varepsilon_{\Delta \ln e x r, t} \quad \varepsilon_{\Delta \operatorname{lnexr}, t} \sim N(0,1)
$$

where $s_{\mathrm{t}}$ is the unobservable regime, and $\varepsilon_{\mathrm{t}}$ is the innovation process with a regimedependent variance-covariance matrix $\Sigma\left(s_{\mathrm{t}}\right)$. Maximum likelihood estimation of (5) yields the 'smoothed' probabilities, representing the ex-post inference about the system being in regime $i$ at year $t$. It is assumed that $s_{t}$ follows an irreducible ergodic two-regime Markov process with the transition matrix $\mathbf{P}$ :

\footnotetext{
${ }^{11}$ The other possible choice of the transition function is given by the exponential transition function: $F\left(\gamma, c ; y_{\mathrm{t}-\mathrm{d}}\right)=1-\exp \left(-\gamma\left(y_{\mathrm{t}-\mathrm{d}}-c\right)^{2}\right)$. One limiting behaviour though of the ESTAR model is that for large values of $\gamma$, this model becomes practically indistinguishable from a linear model.
} 


$$
\mathbf{P}=\left[\begin{array}{ll}
p_{11} & p_{12} \\
p_{21} & p_{22}
\end{array}\right]
$$

Constant transition probabilities $p_{\mathrm{ij}}$ are assumed:

$$
p_{i j}=\operatorname{Pr}\left(s_{t}=j \mid s_{t-1}=i\right), \quad \sum_{j=1}^{2} p_{i j}=1, \quad \forall i, j \in\{1,2\}
$$

The Markov-regime switching model employed here is well-suited to testing whether East Asian currencies exhibit aversion to appreciations because it yields the transition probabilities. Focusing on $p_{11}$ (the probability of remaining in the lower regime, i.e., regime 1, given that the process was in the lower regime at time $t-1$ ) and $p_{22}$ (the probability of remaining in the higher regime, i.e., regime 2 , given that the process was in the higher regime at time $t-1$ ), these transition probabilities can be used to test for asymmetrical exchange rate behaviour. If the probability of remaining in the upper regime is greater than that of remaining in the lower regime, this suggests an aversion of monetary authorities to currency appreciations. Or, more formally:

$$
\operatorname{Pr}\left(s_{t}=2 \mid s_{t-1}=2\right)>\operatorname{Pr}\left(s_{t}=1 \mid s_{t-1}=1\right)
$$

\section{Empirical Results}

Our estimation is based on monthly data for the period 2000:m1 - 2006:m12 for the four inflation-targeting emerging Asian economies of Indonesia, Korea, Philippines and Thailand. The sample period was chosen in view of the fact that the bulk of the reserves accumulation for these economies occurred during this period (i.e. post Asian crisis of 1997-98) as well as to steer clear of the substantial exchange rate instabilities experienced by these economies during the recent global financial crisis of 2007-2009. All nominal exchange rate (domestic currency per US\$) data are obtained from the Pacific Exchange Rate Service (http://fx.sauder.ubc.ca).

In general, the construction of STAR models follows the same steps as in the ARIMABox-Jenkins modeling approach ${ }^{12}$, wherein the modeling cycle consist of model specification, parameter estimation, and diagnostic evaluation. While the linearity tests conducted were easily rejected in favour of the STAR-type models in all cases, in view of the nature of the stated objective of the paper, it is only sensible that we automatically resort to fitting a LSTR2 model to the data and leave it to the diagnostic stage to ascertain whether this choice is appropriately supported by the data. ${ }^{13}$ Table 1 presents the autoregressive order $p$ chosen (first row) and the optimal delay lag length $d$ (second

\footnotetext{
${ }^{12}$ See Box and Jenkins (1970).

${ }^{13}$ For more discussion of this procedure, see Terasvirta (1998).
} 
row).$^{14}$ Autoregressive orders of $p=1$ (Korean won and Thailand baht), $p=2$ (Indonesian rupiah) and $p=6$ (Philippine peso) were chosen. Whereas, optimal delay lag lengths of $d=$ 3 (Korean won, Philippine peso) and $d=5$ (Indonesian rupiah and Thailand baht) were considered.

From these reported $p$ and $d$ values, Table 1 also reports the corresponding estimation results of fitting LSTR2 models for the five East Asian currencies. The majority of the estimated coefficients in Table 1 are statistically different from zero and the ratio between the variance of the LSTR2 model and the variance of the corresponding linear AR model are all below 1, suggesting the suitability of fitting a LSTR2 model for the nominal exchange rate data of the five East Asian currencies. More importantly, a residual diagnostics was conducted to test for the robustness of the LSTR2 specification and the results from these diagnostic tests are presented in Table 2. The residuals from the fitted LSTR2 models all pass the diagnostic tests of autocorrelation (Ljung-Box $Q$ test), conditional heteroscedasticity (ARCH-LM test) and the absence of parameter instability.

In order to provide a meaningful point of comparison, we also repeat the above steps in the construction of an LSTR2 model for the Australian dollar that serve as our benchmark. Table 3 reports the estimation results of fitting a LSTR2 model for the Australian dollar as well as the considered autoregressive order $p$ and optimal delay lag length $d$. As shown in Table 3, though the significance of the estimated coefficients is not as strong as compared to the previously reported coefficients of the fitted LSTR2 models in the case of the four East Asian currencies (Table 1), the variance ratio between the variance of the LSTR2 model and the variance of the corresponding linear AR model are both below 1 , suggesting the appropriate fit of the LSTR2 model to the nominal exchange rate data of this benchmark currency. Moreover, as presented in Table 4, residual diagnostics conducted on the standardised residuals of the Australian dollar reveal that nonlinearity in the nominal exchange rate data of the Australian dollar is adequately characterised by the LSTR2 model.

We now examine our main focus of interest, the lower $\left(c_{\mathrm{L}}\right)$ and upper thresholds $\left(c_{\mathrm{H}}\right)$ from the fitted LSTR2 models. As presented in Table 5, the lower and upper thresholds are at $2.3 \%$ and $6.5 \%$, respectively, for the Indonesian rupiah; $-1 \%$ and $2.1 \%$ for the Korean won; $1.4 \%$ and $5.4 \%$ for the Philippine peso; and, $0.3 \%$ and $1.3 \%$ for the Thailand baht. This shows that in all of the four East Asian currencies considered, the upper threshold, $c_{H}$ is larger than the (absolute value of the) lower threshold, $c_{L}$, which indicates a lower threshold tolerance or aversion of the monetary authorities in these countries to currency appreciations. Interestingly, in marked contrast to the above four East Asian currencies, the lower threshold for our benchmark currency, the Australian dollar, is

\footnotetext{
${ }^{14}$ The reported autoregressive order $p$ were chosen according to the partial autocorrelation function (PACF) and selection criterion such as the Akaike information criterion, whereas the reported optimal delay lag length $d$ were chosen according to the smallest $p$-value of the linearity tests. These results are not reported here for the sake of brevity, but are available upon request from the authors.
} 
approximately equal to the (absolute value of the) lower threshold (-6.2\% and $5.4 \%)$, suggesting a fairly balanced tolerance toward appreciation and depreciation pressures.

We next turn to the estimated results of the univariate Markov-regime switching. Table 6 reports the results for the four East Asian currencies. The estimation results yields plausible estimates of the coefficients in both regimes 1 and 2 and for the most part, the coefficients are statistically significant at conventional levels. The analysis of the standardised residuals as reported in the last two rows of Table 6 provide strong evidence of no residual serial correlation in any of the residual series (Ljung-Box $Q$ test) as well as no evidence of conditional heteroscedasticity (ARCH-LM test), providing further proof that the regime-switching dynamics adopted in this paper captures fairly well the nonlinearity and conditional heteroscedasticity in the nominal exchange rate series.

We also report the estimated results for our benchmark currency in Table 7 . Likewise, the reported results yield plausible estimates of the coefficients as well as being for the most part statistically significant. In addition, the estimated univariate regimeswitching model for the benchmark currency is adequate as the analysis of the standardised residuals show that the remaining residuals are also free from serial correlation and conditional heteroscedasticity.

We now examine the estimated transition probabilities of interest in Table 8. For all of the four East Asian currencies, the probability of remaining in the upper regime $\left(p_{22}\right)$ is greater than that of remaining in the lower regime $\left(p_{11}\right)$, suggesting an aversion to appreciation. Furthermore, the extent of this observed aversion to appreciation varies by degree amongst the four East Asian currencies. For instance, the Indonesian rupiah exemplify the lowest tolerance to appreciations, followed by the Philippine peso. The Korean won and Thailand baht exhibit aversion to appreciation to a relatively lesser degree. In comparison, the probabilities of remaining in the upper and lower regimes are approximately equal in the case of the Australian dollar, confirming once again the official commitment to a flexible regime of exchange rate. In summary, we have robust evidences of asymmetrical exchange rate regime behaviour adopted by the four inflation targeting Asian countries.

\section{Concluding Remarks}

As long as the issue of global imbalances remains, the issue of asymmetrical exchange rate behaviour in this part of the world will always arise and continue to be part of the centre of discussions and debates amongst policy makers and academics. Our study demonstrates that despite the adoption of inflation targeting (IT) regimes, the four Asian economies, which are among the first group of emerging markets to embrace the IT regime framework, do not fully implement market-determined free floating exchange rate regimes. Notwithstanding the observed greater volatility of the respective local currencies, the monetary authorities of these four Asian economies tend to adopt a form of an asymmetrical exchange rate behaviour wherein appreciation pressures are restrained 
more substantially than depreciation pressures. In short, these four Asian economies exemplify aversion to appreciations such that greater flexibility is allowed only for one side of the market. These findings emanate from simple calculations of the exchange market pressure indices for each country which clearly suggests that the four key Asian currencies have indeed largely been under buying pressures during the period of 2000-2006, shortly before the outbreak of the recent sub-prime global financial crisis. Furthermore, instead of allowing their currencies to appreciate significantly, the central banks of these four Asian economies intervened heavily to manage or limit the appreciation pressures. The accompanied substantial reserve accumulation during this period presents further foolproof evidence of a 'leaning against the wind' policy. For lack of better alternatives, Levy-Yeyati and Sturzenegger (2007) label this phenomenon in a catch-all phrase of 'fear of floating in reverse' or 'fear of appreciation'.

Our formal econometric test results according to the smooth transition autoregressive and the Markov regime switching models confirm this hypothesis of aversion to appreciation. Indeed, the findings demonstrate that for the period of observation, the local currencies of Indonesia, Korea, Philippines and Thailand tend to tolerate depreciations more than appreciations and that depreciations tend to occur with greater likelihood than of appreciations. ${ }^{15}$ Interestingly, in contrast, when measured against a comparator or benchmark inflation targeting economy such as Australia, evidence suggests a much more flexible, balanced and symmetrical approach of exchange rate policy adopted by the Reserve Bank of Australia (RBA).

\footnotetext{
${ }^{15}$ For most part of 1990s and early 2000s, maintaining trade competitiveness has frequently been underlined as a key factor to the fear of appreciation phenomena amongst the Asian economies. Future researches are warranted to investigate whether this is still the predominant factor in recent years.
} 


\section{References}

Almekinders, G.J. and Eijjfinger, S.C.W., (1996), “A Friction Model of Daily Bundesbank and Federal Reserve Bank intervention”, Journal of Banking and Finance, Vol. 20(8), pp. 13651380.

Box, G. and Jenkins, G., (1970), Time Series Analysis: Forecasting and Control, San Francisco, Holden Day.

Brenner, M and Sokoler, M., (2010), "Inflation Targeting and Exchange Rate Regimes: Evidence from the Financial Markets", Review of Finance, Vol.14 (2), pp. 295-311.

Calvo, G.A. and Reinhart, C., (2002), "Fear of Floating”,The Quarterly Journal of Economics, Vol. CXVII(2), pp. 379-408. .

Dijk, V.D., Terasvirta, T. and Franses, P.H.. (2002), "Smooth Transition Autoregressive Models - A Survey of Recent Developments", Econometric Reviews, Vol. 21(1), pp. 1-47.

Eichengreen, B. Rose, A. and Wyplosz, C., (1995), "Exchange Market Mayhem: the Antecedents and Aftermaths of Speculative Attacks", Economic Policy, 21, pp. 249-312.

Eichengreen, B. Rose, A. and Wyplosz, C., (1996), “Contagious Currency Crises: First Tests”, Scandinavian Journal of Economics, 98, pp. 463-484.

Fischer, S., (2001), "Exchange Rate Regimes: Is the Bipolar View Correct?" Distinguished Lecture on Economics in Government, Jointly Sponsored by the American Economic Association and the Society of Government Economists, New Orleans, January.

Haldane, A. and Batini, N., (1998), "Forward-Looking Rates for Monetary Policy", National Bureau of Economic Research, Working Paper no. 6543, May.

International Monetary Fund (IMF), (2005), “Does Inflation Targeting Work in Emerging Markets", Chapter 4 of the World Economic Outlook, September, Washington, D.C.

Jansen, K., (2001), "Thailand, financial crisis and monetary policy", Journal of the Asia Pacific Economy, 6(1), 124-152.

Kaminsky, G., Lizondo, S. and Reinhart, C., (1998), "Leading Indicators of Currency Crisis", IMF Staff Papers 45/1, International Monetary Fund, Washington, DC.

Kaminsky, G. and Reinhart, C. (1999), "The Twin Crises: The Causes of Banking and Balance of Payments Problems", American Economic Review 89(3), pp. 537-560.

Leon, H. and Najarian, S., (2005), "Asymmetric Adjustment and Nonlinear Dynamics In Real Exchange Rates", International Journal of Finance and Economics 10(1), pp. 15-39. 
Levy-Yeyati, E. and Sturzenegger, F., (2007), "Fear of Floating in Reverse: Exchange Rate Policy in the 2000s", Mimeo.

Masson, P.R., Savastano, M.A. and Sharma, S., (1997), "The Scope for Inflation Targeting in Developing Countries," IMF Working Paper, WP/97/130.

Pontines, V. and Rajan, R., (2010), "Foreign Exchange Market Intervention and Reserve Accumulation in East Asia: Is there Evidence of 'Fear of Appreciation'?, Mimeo.

Ramachandran, M and Srinivasan, N., (2007), “Asymmetric Exchange Rate Intervention and International Reserve Accumulation in India", Economics Letters, vol. 94(2), pp. 259-265.

Siregar, R.Y. and Lim, C.S., (2010), "“'The Role of Central Banks in Sustaining Economic Recovery and in Achieving Financial Stability", The SEACEN Centre Staff Paper, no. 74.

Srinivasan, N., Mahambare, V. and Ramachandran, M., (2008), "Preference Asymmetry and International Reserve Accretion in India," Applied Economics Letters, pp.1-14.

Svensson L E.O., (2000), “Open-Economy Inflation Targeting”, Journal of International Economics, 50, 2000, 155-183.

Stigler, M., Patnaik, I. and Shah, A., (2009), “Asymmetries in Central Bank Intervention,” Mimeo.

Terasvirta, T. and Anderson, H., (1992), "Characterizing Nonlinearities in Business Cycles Using Smooth Transition Autoregressive Models," Journal of Applied Econometrics, vol. 7(S), pp. S119-36.

Terasvirta, T., (1998), Modelling Economic Relationships with Smooth Transition Regressions, in A. Ullah and D,E.A. Giles (eds.), Handbook of Applied Economic Statistics, New York: Marcel Dekker, pp. 507-552. 
Table 1

Estimation Results for LSTR2 Models of East Asian Currencies

\begin{tabular}{|c|c|c|c|c|}
\hline & $\begin{array}{l}\text { Indonesian } \\
\text { Rupiah }\end{array}$ & $\begin{array}{l}\text { Korean } \\
\text { Won }\end{array}$ & $\begin{array}{c}\text { Philippine } \\
\text { Peso }\end{array}$ & $\begin{array}{c}\text { Thailand } \\
\text { Baht }\end{array}$ \\
\hline$p$ & 2 & 1 & 6 & 1 \\
\hline$d$ & 5 & 3 & 3 & 5 \\
\hline & & linear part & & \\
\hline intercept & $-0.010(0.01)$ & $-0.004(0.00)$ & $-0.028(0.01)^{*}$ & $-0.009(0.00)^{* *}$ \\
\hline$(\Delta \ln e x r)_{t-1}$ & $1.714(0.35)^{* * *}$ & $0.511(0.19)^{* *}$ & & $1.375(0.37)^{* * *}$ \\
\hline$(\Delta \ln e x r)_{t-2}$ & $1.862(0.47)^{* * *}$ & & & \\
\hline$(\Delta \ln e x r)_{t-3}$ & & & $1.777(0.71)^{* *}$ & \\
\hline$(\Delta \ln e x r)_{t-4}$ & & & $-1.582(0.29)^{* * *}$ & \\
\hline \multicolumn{5}{|l|}{$(\Delta \ln e x r)_{t-5}$} \\
\hline \multirow[t]{2}{*}{$(\Delta \ln e x r)_{t-6}$} & & & $0.393(0.18)^{* *}$ & \\
\hline & & non-linear part & & \\
\hline intercept & $0.012(0.01)$ & $0.004(0.00)$ & $0.028(0.01)^{*}$ & $0.008(0.00)^{*}$ \\
\hline$(\Delta \ln e x r)_{t-1}$ & $-1.686(0.35)^{* * *}$ & $-0.633(0.27)^{* *}$ & $0.198(0.11)^{*}$ & $-1.181(0.39)^{* * *}$ \\
\hline$(\Delta \ln e x r)_{t-2}$ & $-2.058(0.48)^{* * *}$ & & $0.136(0.14)$ & \\
\hline$(\Delta \ln e x r)_{t-3}$ & & & $-1.813(0.72)^{* *}$ & \\
\hline$(\Delta \ln e x r)_{t-4}$ & & & $1.489(0.31)^{* * *}$ & \\
\hline$(\Delta \ln e x r)_{t-5}$ & & & $-0.018(0.14)$ & \\
\hline$(\Delta \ln e x r)_{t-6}$ & & & $-0.273(0.22)$ & \\
\hline 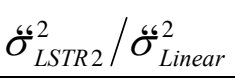 & 0.73 & 0.95 & 0.86 & 0.96 \\
\hline
\end{tabular}

$p$ is the number of lags in the linear autoregressive model; $d$ is the optimal delay parameter; Numbers in parentheses are standard errors. Significance levels: ${ }^{*} 10 \%,{ }^{* *} 5 \%,{ }^{* *} 1 \%$. 
Table 2

Diagnostic Test Results for LSTR2 Models of East Asian Currencies

\begin{tabular}{ccccc}
\hline & Indonesian Rupiah & Korean Won & Philippine Peso & Thailand Baht \\
\hline Residual tests & & & & \\
Ljung-Box $Q$ & 0.547 & 0.716 & 0.492 & 0.868 \\
ARCH-LM(8) & 0.548 & 0.584 & 0.784 & 0.866 \\
Parameter constancy & & & & \\
H1 & & & & \\
H2 & 0.254 & 0.319 & 0.338 & 0.806 \\
H3 & 0.110 & 0.621 & 0.356 & 0.932 \\
& 0.004 & 0.862 & 0.181 & 0.813 \\
\hline
\end{tabular}

The Table presents the $p$-values of diagnostic tests for the corresponding models shown in Table 1. 
Table 3

Estimation Results for LSTR2 Models of the Australian Dollar

\begin{tabular}{|c|c|}
\hline & Australian Dollar \\
\hline$p$ & 1 \\
\hline \multirow[t]{2}{*}{$d$} & 6 \\
\hline & linear part \\
\hline \multirow{3}{*}{$\begin{array}{l}\text { intercept } \\
(\Delta \ln e x r)_{t-1}\end{array}$} & $-0.005(0.00)^{*}$ \\
\hline & $0.125(0.12)$ \\
\hline & nonlinear part \\
\hline intercept & $0.426(2.82)$ \\
\hline$(\Delta \ln e x r)_{t-1}$ & $12.414(12.87)$ \\
\hline$\breve{\mathscr{E}}_{\text {LSTR2 } 2}^{2} / \breve{\mathscr{E}}_{\text {Linear }}^{2}$ & 0.77 \\
\hline
\end{tabular}

$p$ is the number of lags in the linear autoregressive model; $d$ is the optimal delay parameter; Numbers in parentheses are standard errors. Significance levels: ${ }^{*} 10 \%,{ }^{* *} 5 \%$. 
Table 4

Diagnostic Test Results for LSTR2 Models of the Australian Dollar

\begin{tabular}{cc}
\hline & Australian Dollar \\
\hline Residual tests & \\
Ljung-Box $Q$ & 0.212 \\
ARCH-LM(8) & 0.856 \\
Parameter constancy & \\
H1 & \\
H2 & 0.915 \\
H3 & 0.815 \\
\hline
\end{tabular}

The Table presents the $p$-values of diagnostic tests for the corresponding models shown in Table 3 . 
Table 5

Threshold Values

\begin{tabular}{lll}
\hline$C_{\mathrm{L}}$ & $C_{\mathrm{H}}$ \\
\hline
\end{tabular}

\section{East Asian currencies}

$\begin{array}{ccc}\text { Indonesian rupiah } & 0.023(0.00)^{* * *} & 0.065(0.00)^{* * *} \\ \text { Korean won } & -0.010(0.00)^{* * *} & 0.021(0.01)^{* *} \\ \text { Philippine peso } & 0.014(0.00)^{* * *} & 0.054(0.00)^{* * *} \\ \text { Thailand baht } & 0.003(0.00)^{* * *} & 0.013(0.00)^{* * *}\end{array}$

\section{Benchmark currency}

Australian dollar $\quad-0.062(0.02)^{* *} \quad 0.054(0.01)^{* *}$

Numbers in square brackets are $p$-values.

Significance levels: ${ }^{* *} 5 \%,{ }^{* * *} 1 \% . c_{\mathrm{L}}, c_{\mathrm{H}}$ are the lower and higher threshold values, respectively. 
Table 6

Estimation Results for Regime Switching Models of East Asian Currencies

\begin{tabular}{|c|c|c|c|c|}
\hline & $\begin{array}{c}\text { Indonesian } \\
\text { Rupiah }\end{array}$ & $\begin{array}{c}\text { Korean } \\
\text { Won }\end{array}$ & $\begin{array}{l}\text { Philippine } \\
\text { Peso }\end{array}$ & $\begin{array}{c}\text { Thailand } \\
\text { Baht }\end{array}$ \\
\hline $\begin{array}{l}\text { intercept } \\
(\Delta \ln e x r)_{t-1} \\
(\Delta \ln e x r)_{t-2} \\
(\Delta \ln e x r)_{t-3} \\
(\Delta \ln e x r)_{t-4} \\
\left(\Delta \ln e_{t-5}\right)_{t-5} \\
(\Delta \ln \text { exr })_{t-6}\end{array}$ & $\begin{array}{c}-0.000(0.015) \\
4.339(0.521)^{* * *} \\
0.569(0.198)^{* * *}\end{array}$ & $\begin{array}{c}\text { Regime } 1 \\
-0.002(0.002) \\
-0.333(0.169)^{* *}\end{array}$ & $\begin{array}{c}-0.003(0.004) \\
-0.408(0.193)^{* *} \\
0.733(0.239)^{* * *} \\
-0.520(0.223)^{* *} \\
-0.277(0.142)^{* *} \\
-0.426(0.240)^{*} \\
0.078(0.213)\end{array}$ & $\begin{array}{c}-0.002(0.001)^{* * *} \\
0.167(0.064)^{* * *} \\
-0.529(0.068)^{* * *} \\
0.495(0.068)^{* * *}\end{array}$ \\
\hline $\begin{array}{l}\text { intercept } \\
(\Delta \ln e x r)_{t-1} \\
(\Delta \ln e x r)_{t-2} \\
(\Delta \ln e x)_{t-3} \\
(\Delta \ln e x r)_{t-4} \\
\left(\Delta \ln e_{t-5}\right)_{t-5} \\
(\Delta \ln \text { exr })_{t-6}\end{array}$ & $\begin{array}{l}0.002(0.003) \\
0.035(0.092) \\
0.038(0.145)\end{array}$ & $\begin{array}{c}\text { Regime } 2 \\
-0.002(0.002) \\
0.631(0.209)^{* * *}\end{array}$ & $\begin{array}{c}-0.000(0.003) \\
0.562(0.139)^{* * *} \\
-0.233(0.142) \\
0.360(0.095)^{* * *} \\
0.117(0.265) \\
0.008(0.121) \\
0.090(0.114)\end{array}$ & $\begin{array}{c}-0.002(0.001)^{* * *} \\
0.442(0.147)^{* * *} \\
0.097(0.156) \\
-0.047(0.154)\end{array}$ \\
\hline $\begin{array}{l}\text { Ljung-Box } Q \\
\text { ARCH-LM(8) }\end{array}$ & $\begin{array}{l}{[0.6302]} \\
{[0.6899]}\end{array}$ & $\begin{array}{l}{[0.5083]} \\
{[0.2137]}\end{array}$ & $\begin{array}{l}{[0.7475]} \\
{[0.7324]}\end{array}$ & $\begin{array}{l}{[0.3491]} \\
{[0.6378]}\end{array}$ \\
\hline
\end{tabular}

Numbers in parentheses and square brackets are standard errors and $p$-values, respectively. Significance levels: * $10 \%, * * 5 \%,{ }^{* * *} 1 \%$. 
Table 7

Estimation Results for Regime Switching Models of the Australian Dollar

\begin{tabular}{cc}
\hline & Regime 1 \\
Intercept & $-0.005(0.010)$ \\
$(\Delta \ln e x r)_{t-1}$ & $0.252(0.106)^{* *}$ \\
$(\Delta \ln e x r)_{t-2}$ & $-0.241(0.107)^{* *}$ \\
$(\Delta \ln \text { exr })_{t-3}$ & $0.218(0.103)^{* *}$ \\
& Regime 2 \\
& \\
Intercept & $0.027(0.011)^{* *}$ \\
$(\Delta \ln \text { exr })_{t-1}$ & $0.067(0.340)$ \\
$(\Delta \ln \text { exr })_{t-2}$ & $-0.425(0.312)$ \\
$(\Delta \ln \text { exr })_{t-3}$ & $-0.603(0.339)^{*}$ \\
& {$[0.8337]$} \\
Ljung-Box $Q$ & {$[0.0947]$} \\
ARCH-LM $(8)$ & \\
\hline
\end{tabular}

Numbers in parentheses and square brackets are standard errors and $p$-values, respectively. Significance levels: $* 10 \%, * * 5 \%, * * * 1 \%$. 
Table 8

Transition Probabilities

$p_{11}$

$p_{22}$

\section{East Asian currencies}

Indonesian Rupiah

$0.0245 \quad 0.9268$

Korean Won

$0.3896 \quad 0.5765$

Philippine Peso

$0.1988 \quad 0.6065$

Thailand Baht

$0.6014 \quad 0.8524$

\section{Benchmark currency}

Australian Dollar $\quad 0.9999 \quad 0.9317$ 


\section{Figure 1}

Monthly (\%) Exchange Rate Change against the US Dollar
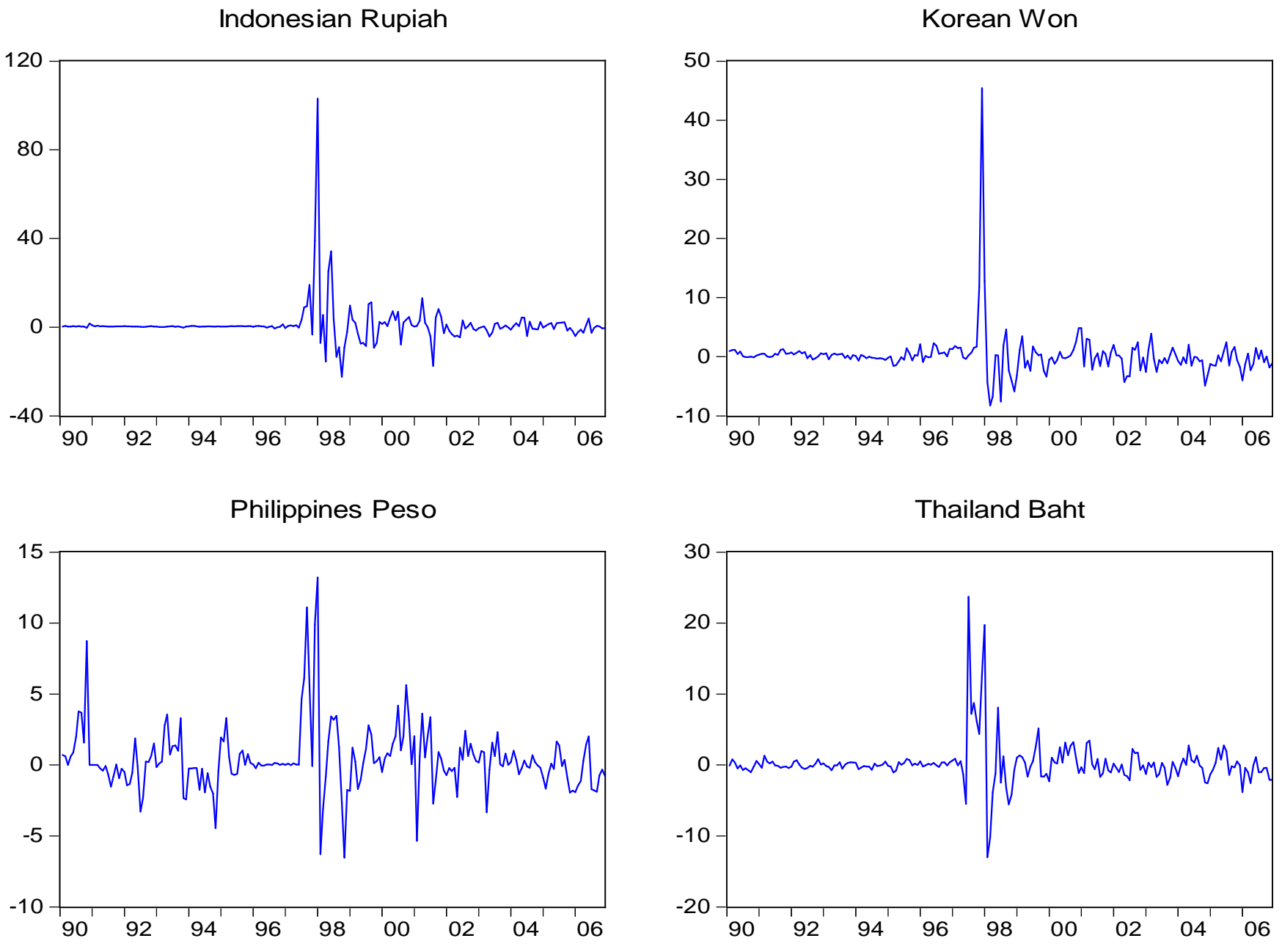
Figure 2

\section{KLR EMPs}

Indonesian Rupiah

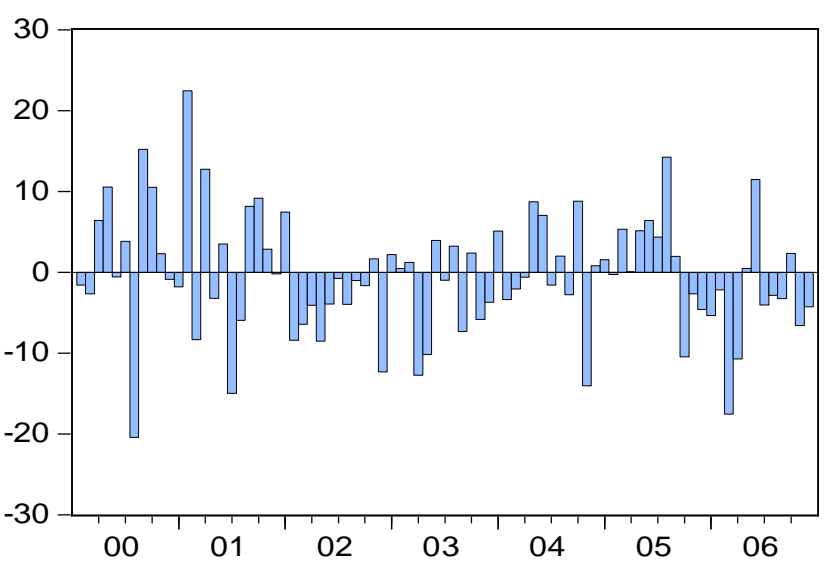

Philippines Peso

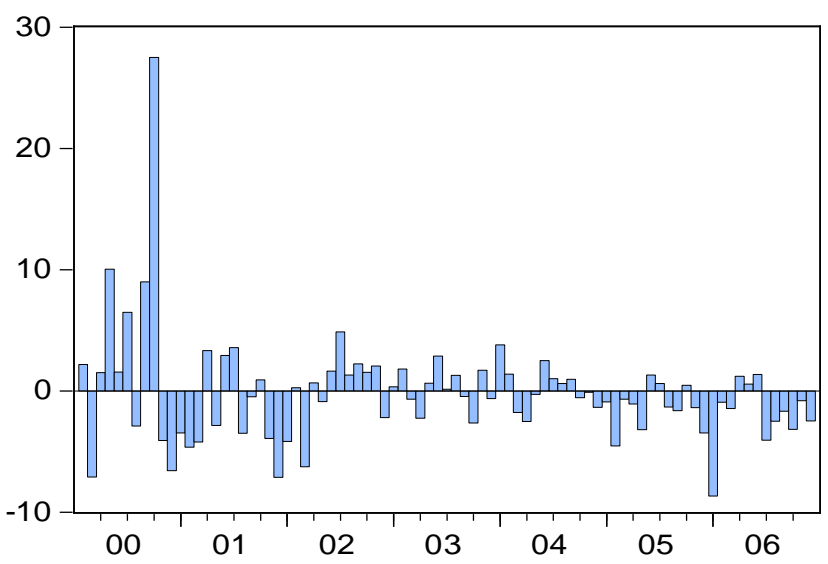

Korean Won

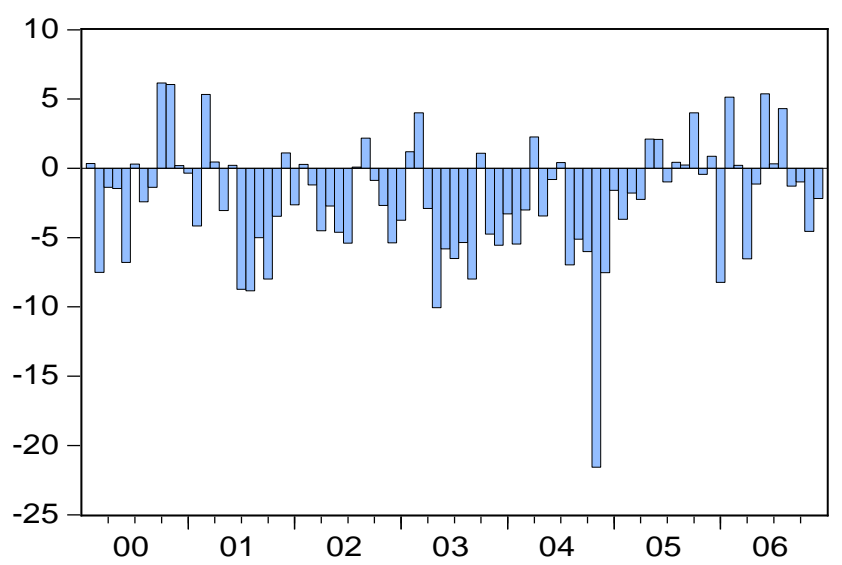

Thailand Baht

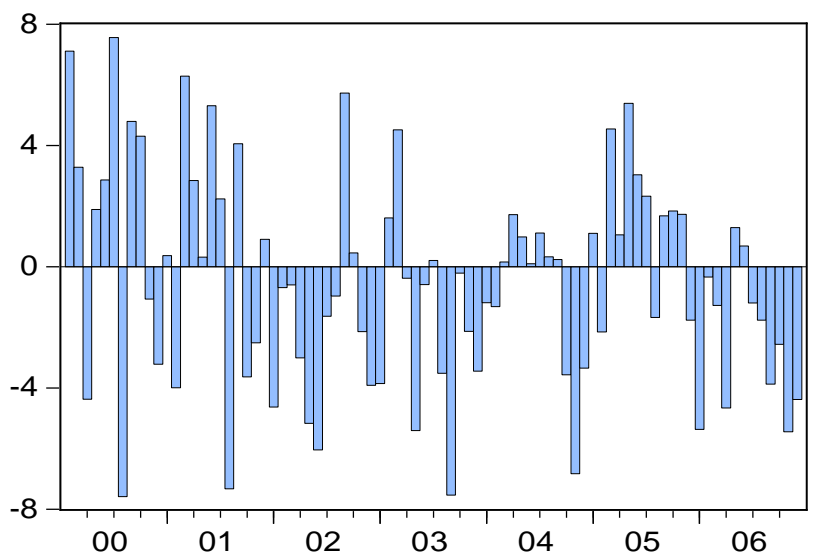

